\title{
TOTAL UNCERTAINTY OF RADIOCARBON MEASUREMENTS OF MARINE DISSOLVED ORGANIC CARBON AND METHODOLOGICAL RECOMMENDATIONS
}

\author{
Ellen R M Druffel ${ }^{1} \bullet$ Sheila Griffin $\bullet$ Brett D Walker • Alysha I Coppola • Danielle S Glynn \\ Department of Earth System Science, University of California Irvine, Irvine, California 92697-3100, USA.
}

\begin{abstract}
We report results of duplicate measurements of dissolved organic carbon concentrations ([DOC] as $\mu \mathrm{M})$ and $\Delta^{14} \mathrm{C}$ in seawater in order to assess the total uncertainty of reported [DOC] and $\Delta^{14} \mathrm{C}$ measurements via the UV oxidation method. In addition, pure International Atomic Energy Agency standards analyzed over a 4-yr period are evaluated. We find the total uncertainty of $\Delta^{14} \mathrm{C}$ measurements to be $\pm 4.0 \%$. However, in samples that were thawed, subsampled, and refrozen prior to UV oxidation, the total uncertainty of $\Delta^{14} \mathrm{C}$ measurements is on the order of $\pm 10 \%$. The [DOC] measurements of these samples were also higher by $1.8 \pm 0.3 \mu \mathrm{M}$. The reason(s) for these documented increases in total [DOC] and $\Delta^{14} \mathrm{C}$ uncertainty are unclear. In order to minimize any effects on sample measurements, we recommend the following: 1) regular monitoring of duplicate samples, DOC standards, and diluent (Milli-Q ${ }^{\mathrm{TM}}$ ) water for $\Delta^{14} \mathrm{C}$ and [DOC] measurements; 2) thawing a sample immediately and only once prior to UV oxidation; 3) avoid the use of DOC-leachable plumbing (such as PVC pipe) in both water systems feeding and within Milli-Q systems; and 4) consider the use of DOC-free diluents (i.e. pre-UV oxidized Milli-Q or sample water).
\end{abstract}

\section{INTRODUCTION}

Few global measurements of dissolved organic carbon (DOC) $\Delta^{14} \mathrm{C}$ have been made in the ocean despite its central importance for evaluating the source and cycling of this largest of organic carbon pools in the ocean. Despite $35 \mathrm{yr}$ of using UV oxidation to measure DOC $\Delta{ }^{14} \mathrm{C}$, the total uncertainty of sample measurements has not been rigorously evaluated.

Williams et al. (1969) presented the first $\Delta^{14} \mathrm{C}$ measurements of DOC in seawater. In this study, $200 \mathrm{~L}$ of seawater were required for a single measurement. With the advent of accelerator mass spectrometry (AMS) analysis of ${ }^{14} \mathrm{C}$, the amount of seawater needed for a measurement of DOC was reduced to $5 \mathrm{~L}$ (Williams and Druffel 1987). Currently, samples as small as $0.03 \mathrm{~L}$ can be analyzed for DOC $\Delta^{14} \mathrm{C}$ (Beaupré et al. 2007). Oxidation using ultraviolet (UV) irradiation is currently the chosen method for seawater DOC $\Delta^{14} \mathrm{C}$ analysis. Beaupré et al. (2007) reported development of a modified, UV oxidation method for measuring concentration, $\Delta^{14} \mathrm{C}$ and $\delta^{13} \mathrm{C}$ values in marine DOC. Small samples $(0.03-0.65 \mathrm{~L})$ were diluted with pre-irradiated Milli- $\mathrm{Q}^{\mathrm{TM}}(\mathrm{MQ})$ water prior to UV oxidation. Griffin et al. (2010) reported a revised technique that used MQ water without pre-irradiation to dilute small samples that reduced the amount of time required to run a diluted sample from 2 days to 1 day.

We assess the total uncertainty of DOC concentrations ([DOC] as $\mu \mathrm{M})$ and $\Delta^{14} \mathrm{C}$ results employing the revised method of Griffin et al. (2010) using 2 sample groups: a) measurement of duplicate seawater samples collected from the same Niskin bottle; and b) measurement of pure International Atomic Energy Agency (IAEA) and internal standards, both added to raw MQ water (without preUV oxidation). We report that duplicate seawater samples have DOC $\Delta{ }^{14} \mathrm{C}$ values with a total uncertainty of $\pm 4.0 \%$ (for half-modern samples).

\section{METHODS}

We use the dilution method for UV photo-oxidation (UVox) of seawater DOC described previously (Griffin et al. 2010). Small DOC samples ( 0.40 L) are diluted with $18.2 \mathrm{M} \Omega \mathrm{MQ}$ water prior to oxi-

${ }^{1}$ Corresponding author. Email: edruffel@uci.edu. 


\section{E R M Druffel et al.}

dation. The volumes of sample and MQ water are measured using a calibrated cathetometer in a quartz reactor and acidified with $1 \mathrm{~mL} 85 \%$ phosphoric acid. The dissolved inorganic carbon (DIC) is sparged from the sample using $\mathrm{He}$ gas, then the DOC is oxidized to $\mathrm{CO}_{2}$ using a $1200 \mathrm{~W}$ mediumpressure, mercury arc, UV lamp for $4 \mathrm{hr}$. The $\mathrm{CO}_{2}$ is collected cryogenically, cleaned of water, and manometrically quantified. Separate aliquots of the $\mathrm{CO}_{2}$ are analyzed for $\delta^{13} \mathrm{C}$ and $\Delta^{14} \mathrm{C}$ using standard techniques (Vogel et al. 1987; Southon et al. 2004).

Seawater samples were collected from Niskin bottles and frozen in 1-L amber glass Boston round bottles at $-20{ }^{\circ} \mathrm{C}$. Prior to sample collection, the glass storage bottles were cleaned with $10 \% \mathrm{HCl}$ and MQ water then combusted at $550{ }^{\circ} \mathrm{C}$ for at least $2 \mathrm{hr}$. Samples were obtained from CLIVAR/ Repeat Hydrography cruises in the S Pacific (line P6) and S Atlantic (line A10) during 2010 and 2011 , respectively. Only those samples analyzed in duplicate are reported here. Results and environmental interpretations for the remaining samples will be reported in a separate publication.

\section{RESULTS AND DISCUSSION}

\section{$\Delta^{14} \mathrm{C}$ Results of Seawater}

Duplicate $\Delta^{14} \mathrm{C}$ analyses are listed for each of 11 seawater samples collected in 2010 (P6) and 2011 (A10) in Table 1. The absolute values of $\Delta^{14} \mathrm{C}$ differences between each pair of duplicates $\left(\left|\Delta \Delta^{14} \mathrm{C}\right|=\right.$ $\left.\left|\Delta^{14} \mathrm{C}_{\mathrm{A}}-\Delta \Delta^{14} \mathrm{C}_{\mathrm{B}}\right|\right)$ range from $2.1 \%$ to $14.8 \%$, with an average of $6.8 \pm 3.8 \%$ ( $\left.n=11\right)$. Most of the variability is accounted for by 5 of the duplicates $(\mathrm{P} 6-2 \mathrm{~A} / \mathrm{B}, \mathrm{P} 6-3 \mathrm{~A} / \mathrm{B}, \mathrm{P} 6-4 \mathrm{~A} / \mathrm{B}, \mathrm{A} 10-4 \mathrm{~A} / \mathrm{B}$, and A10-6A/B) whose $\left|\Delta \Delta^{14} \mathrm{C}\right|$ values were $8 \%$ or higher (average $10 \pm 2.6 \%$ ). The average of the remaining $6\left|\Delta \Delta^{14} \mathrm{C}\right|$ values is $4.0 \pm 1.4 \%$. We also note that of the 5 duplicates whose $\left|\Delta \Delta^{14} \mathrm{C}\right|$ values are largest, all of the second analyses (labeled "B" in Table 1) were measured between 21 and 176 days after the first analyses (labeled " $\mathrm{A}$ "; Figure 1a). The remaining 6 duplicates, whose $\Delta \Delta^{14} \mathrm{C}$ values ranged from 2.1 to $5.6 \%$, were measured within 1 to 5 days of each other (Table 1). In other words, better agreement between duplicate $\Delta^{14} \mathrm{C}$ values is achieved when the 2 halves of the sample are measured within 5 days of each other.

$\delta^{13} \mathrm{C}$ measurements of the DOC duplicates are listed in Table 1 and range from $-21.9 \%$ to $-20.5 \%$. The $\delta^{13} \mathrm{C}$ differences between the second and first analyses $\left(\Delta \delta^{13} \mathrm{C}\right.$, available for only 8 of the 11 duplicates) range from $0.1 \%$ to $-0.9 \%$ (average $-0.3 \pm 0.3 \%$ ), and is $\leq 0$ for 7 of 8 of the duplicates. Most of the variability is due to 2 of the duplicates $(\mathrm{A} 10-4 \mathrm{~A} / \mathrm{B},-0.6 \%$, and $\mathrm{A} 10-6 \mathrm{~A} / \mathrm{B},-0.9 \%$ ) that were measured 21 and 80 days apart, respectively; however, the difference between P6-2A and -2B was only $-0.3 \%$ and they were measured 176 days apart. So, though the second oxidation is nearly always lower in $\delta^{13} \mathrm{C}$ value than the first oxidation, the difference between their $\delta^{13} \mathrm{C}$ values does not appear to be affected by the number of days that they are measured apart.

We obtain [DOC] measurements using mass and volume of $\mathrm{CO}_{2}$ generated during the UV oxidation process (Table 1). The differences between the second and first [DOC] values $(\triangle[\mathrm{DOC}])$ range from -4.8 to $2.1 \mu \mathrm{M}$, with an average of $0.2 \pm 1.2 \mu \mathrm{M}(n=11)$. The $\Delta[\mathrm{DOC}]$ for 5 duplicates that were measured from 21 to 176 days apart from each other averaged $1.8 \pm 0.3 \mu \mathrm{M}$ and the second oxidation was always higher than the first (Figure 1b). This was not the case for the 6 duplicates that were UV oxidized $<6$ days apart (average difference was $-1.1 \pm 2.1 \mu \mathrm{M}$ ). Therefore, it appears that $[\mathrm{DOC}]$ increased in samples that had been thawed and refrozen for 21 days or longer. The cause of the increase in $[\mathrm{DOC}]$ is unclear. Possible mechanisms contributing to higher [DOC] could include small contributions of DOC via bacterial cell lysis during sample freeze/thaw, contamination from the bottle cap (Teflon ${ }^{\mathrm{TM}}$-lined and cleaned prior to use with detergent and water then rinsed with $10 \% \mathrm{HCl}$ ), and possible chemoautotrophic production of DOC from fixation of DIC during sample 
Total Uncertainty of ${ }^{14} \mathrm{C}$ Measurements of Marine DOC

Table 1 Concentration of $\Delta^{14} \mathrm{C}$ values of DOC in duplicate seawater samples UV oxidized in MQ water.

\begin{tabular}{|c|c|c|c|c|c|c|c|c|c|c|}
\hline Sample & $\begin{array}{l}\text { UCID } \\
\#\end{array}$ & $\begin{array}{l}\text { UCIAMS } \\
\#\end{array}$ & $\begin{array}{l}\text { Date } \\
\text { oxidized }\end{array}$ & $\begin{array}{c}\Delta \\
\text { days }\end{array}$ & $\begin{array}{l}{[\mathrm{DOC}]} \\
\mu \mathrm{M}\end{array}$ & $\begin{array}{l}\Delta[\mathrm{DOC}] \\
\mu \mathrm{M}\end{array}$ & $\begin{array}{l}\Delta^{14} \mathrm{C} \\
\% \text { o }\end{array}$ & $\begin{array}{l}\left|\Delta \Delta^{14} \mathrm{C}\right| \\
\% \text { o }\end{array}$ & $\begin{array}{l}\delta^{13} \mathrm{C} \\
\% 0\end{array}$ & $\Delta \delta^{13} \mathrm{C}$ \\
\hline P6-1A & 13023 & 86420 & $9 / 22 / 10$ & 1 & 33.8 & 1.3 & -509.5 & 2.8 & -21.1 & -0.2 \\
\hline P6-1B & 13024 & 86421 & $9 / 23 / 10$ & & 35.1 & & -506.7 & & -21.3 & \\
\hline P6-2A & 13032 & 86206 & $10 / 19 / 10$ & 176 & 40.1 & 1.5 & -377.2 & 9.3 & -20.9 & -0.3 \\
\hline P6-2B & 13361 & 95245 & 4/13/11 & & 41.6 & & -367.9 & & -21.1 & \\
\hline P6-3A & 13033 & 86207 & $10 / 29 / 10$ & 173 & 32.6 & 2.1 & -528.0 & 10.3 & & \\
\hline P6-3B & 13365 & 95248 & $4 / 20 / 11$ & & 34.7 & & -538.3 & & -22.0 & \\
\hline P6-4A & 15741 & 104843 & $10 / 27 / 11$ & 148 & 44.8 & 1.8 & -352.5 & 14.8 & & \\
\hline P6-4B & 16252 & 109248 & $3 / 23 / 12$ & & 46.6 & & -337.7 & & -21.5 & \\
\hline P6-5A & 15749 & 104851 & $11 / 14 / 11$ & 1 & 42.4 & -1.0 & -415.6 & 5.4 & -21.6 & 0.1 \\
\hline P6-5B & 15750 & 104852 & $11 / 15 / 11$ & & 41.4 & & -410.2 & & -21.5 & \\
\hline A $10-1 A$ & 16249 & 109063 & $3 / 16 / 12$ & 5 & 39.8 & -4.8 & -474.7 & 2.1 & -21.4 & 0.0 \\
\hline A $10-1 B$ & 16250 & 109064 & $3 / 21 / 12$ & & 35.0 & & -472.6 & & -21.4 & \\
\hline A $10-2$ A & 16206 & 109050 & $1 / 31 / 12$ & 1 & 38.0 & -0.1 & -476.7 & 5.6 & -21.2 & 0.0 \\
\hline A $10-2 B$ & 16207 & 109051 & $2 / 1 / 12$ & & 37.9 & & -482.3 & & -21.2 & \\
\hline A $10-3 A$ & 16713 & 115058 & $9 / 12 / 12$ & 1 & 60.6 & -2.2 & -261.4 & 4.4 & -21.9 & \\
\hline A $10-3 B$ & 16714 & 115059 & $9 / 13 / 12$ & & 58.4 & & -257.0 & & & \\
\hline A $10-4 A$ & 16697 & 115052 & $8 / 21 / 12$ & 21 & 35.3 & 2.1 & -484.4 & 8.0 & -21.3 & -0.6 \\
\hline A $10-4 B$ & 16712 & 115062 & $9 / 11 / 12$ & & 37.4 & & -476.4 & & -21.8 & \\
\hline A $10-5 A$ & 16709 & 115060 & $9 / 6 / 12$ & 1 & 37.9 & 0.0 & -468.4 & 3.4 & -20.7 & -0.3 \\
\hline A $10-5 B$ & 16710 & 115061 & $9 / 7 / 12$ & & 37.9 & & -465.0 & & -21.0 & \\
\hline A $10-6$ A & 16398 & 113829 & $5 / 29 / 12$ & 80 & 48.7 & 1.4 & -286.8 & 9.1 & -20.5 & -0.9 \\
\hline A $10-6 B$ & 16696 & & $8 / 17 / 12$ & & 50.1 & & -295.9 & & -21.4 & \\
\hline
\end{tabular}

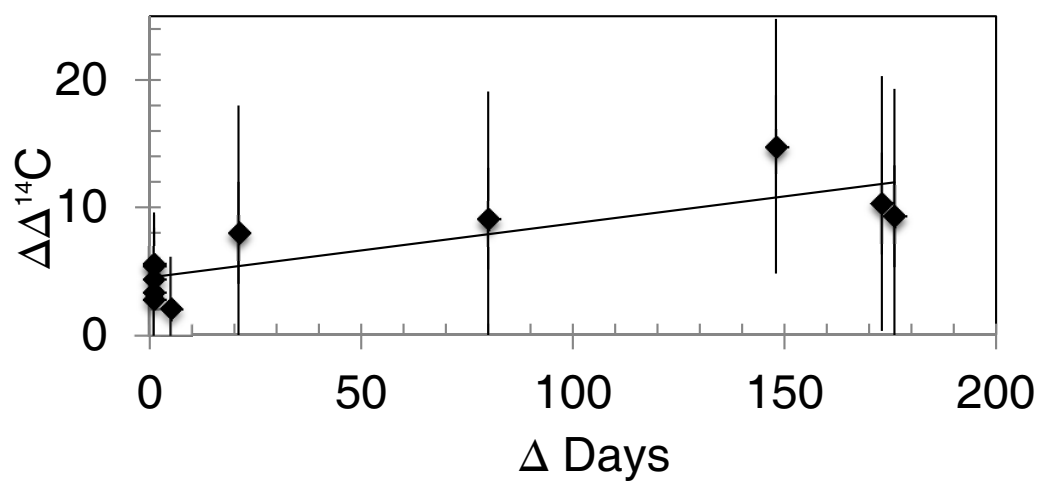

Figure 1a Number of days ( $\Delta$ days) between duplicate UV oxidations vs. the absolute value of the $\Delta^{14} \mathrm{C}$ differences between duplicate seawater measurements $\left(\left|\Delta \Delta^{14} \mathrm{C}\right|\right)$. The coefficient of determination $\left(\mathrm{R}^{2}\right)$ for the least-squares fit line is $0.682(n=11, p<.002)$. Error bars are $\pm 4 \%$ for duplicates run $\leq 5$ days apart, and $\pm 10 \%$ for duplicates run $\geq 21$ days apart (see text for detail).

thawing. However, the latter 2 mechanisms are unlikely. Regardless of a specific mechanism that adds DOC to the samples during storage, our results indicate that it is important to analyze sample duplicates within a short period of time. A solution to this problem could be to collect/measure duplicate seawater samples using the entire volume of water in separate bottles (e.g. two 500-mL bottles rather than a single 1-L bottle as was done for this study).

We conclude that the reported uncertainty for our DOC $\Delta^{14} \mathrm{C}$ measurements (whose values range from $-291 \%$ to $-533 \%$ ) using dilution by MQ water is $\pm 4.0 \%$. This is for samples that have been run within 5 days of the initial thawing of the seawater sample. For samples that had been stored fro- 


\section{E R M Druffel et al.}

zen 21 days, the reported uncertainty is larger $( \pm 10 \%)$, although results are based on a small number of samples.

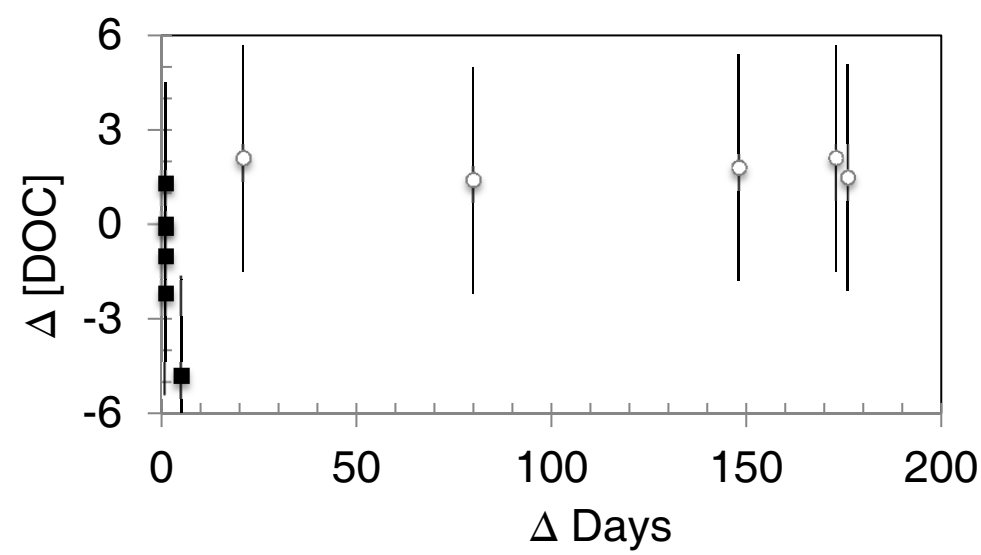

Figure 1b Number of days ( $\Delta$ days) between duplicate UV oxidations vs. [DOC] differences (2nd minus 1st) for duplicate seawater measurements. Note that all duplicates measured $\geq 21$ days apart were consistently higher in [DOC]. Error bars are $\pm 1.6 \mu \mathrm{M}$ for duplicates run $\leq 5$ days apart, and $\pm 3.6 \mu \mathrm{M}$ for duplicates run $\geq 21$ days apart (see text for detail).

The reported uncertainty for [DOC] measurements that ranged from 33-50 $\mu \mathrm{M}$ using our procedure is $\pm 1.6 \mu \mathrm{M}$ for samples that have been run within 5 days of the initial thawing of the seawater sample. For samples that have been stored frozen for $\geq 21$ days, the reported uncertainty is larger.

\section{$\Delta^{14} \mathrm{C}$ Results of Standards}

As a part of our DOC $\Delta^{14} \mathrm{C}$ measurement, we routinely analyze 3 standards: OX-I, IAEA-C8, and IAEA-C7 in raw MQ water. In 2012, we added the amino acid glycine (99+\%; ACROS Organics, $220911000)$ to use as a ${ }^{14} \mathrm{C}$-free standard for the DOC process. The use of ${ }^{14} \mathrm{C}$-free glycine as a UVox DOC standard has several advantages over traditional IAEA ${ }^{14} \mathrm{C}$ standards (i.e. IAEA-C8 oxalic acid). These advantages include 1 ) the use of a completely ${ }^{14} \mathrm{C}$-free standard (vs. IAEA-C8 $\mathrm{Fm}=0.1526$ ) allows for a more accurate assessment of modern extraneous carbon contributions; 2) oxalic acid is not chemically representative of seawater DOC, and the use of a compound with more functional groups and heterogeneous atoms (i.e. $\mathrm{N}$ content) should better simulate seawater DOC in the UV reactor; and 3) amino acids such as glycine are efficient absorbers of UV light, and thus photo-reactive compounds.

Results of standards run during the 2008-2012 period are shown in Table 2. During the 4-yr study period, we analyzed 39 OX-I standards and obtained an average Fm of $1.0396 \pm 0.0072$. This value is within \pm 0.0004 of the consensus value of 1.0400 . Eight IAEA-C8 standards were run, with an average $\mathrm{Fm}$ of $0.1531 \pm 0.0031$; this value agrees with the consensus value of $0.1503 \pm 0.0017$. We obtained an average value of $0.4919 \pm 0.0071$ for 17 analyses of the IAEA-C7 standard that agrees with the consensus value of $0.4953 \pm 0.0012$. Four glycine standards were run and we obtained an average value of $0.0073 \pm 0.0032$. All DOC $\Delta^{14} \mathrm{C}$ measurements are corrected for the presence of extraneous carbon introduced during the processing, which is assessed regularly by processing the DOC obtained from UV oxidation of the MQ water used for dilution (Griffin et al. 2010) (see below). 
Total Uncertainty of ${ }^{14} \mathrm{C}$ Measurements of Marine DOC

Table 2 Average Fm values of standards run using the UV oxidation method between January 2009 and January 2013, and consensus values for the standards.

\begin{tabular}{lrlll}
\hline Standards & \multicolumn{1}{c}{$n$} & Average $\mathrm{Fm} \pm 1 \sigma$ & Consensus Fm & $\Delta \mathrm{Fm}$ \\
\hline OX-I & 39 & $1.0396 \pm 0.0072$ & 1.0400 & 0.0004 \\
IAEA-C8 & 8 & $0.1531 \pm 0.0031$ & $0.1503 \pm 0.0017$ & 0.0028 \\
IAEA-C7 & 17 & $0.4919 \pm 0.0071$ & $0.4953 \pm 0.0012$ & 0.0034 \\
Glycine & 4 & $0.0073 \pm 0.0032$ & & \\
\hline
\end{tabular}

\section{Extraneous Carbon and Possible Memory in the UV Oxidation Apparatus}

As a part of our DOC $\Delta{ }^{14} \mathrm{C}$ measurement, we routinely measure MQ water that is used to dilute our seawater samples and standards. Griffin et al. (2010) reported that the Fm values of MQ water analyzed between May 2008 and August 2009 ranged from 0.209 to $0.481(n=18)$. The [DOC] values of the MQ water were consistently between 0.8 and $1.1 \mu \mathrm{M}$; graphite targets made from these samples were between 8 and $14 \mu \mathrm{g}$ carbon. We present all of the Fm values obtained for the MQ water DOC samples analyzed between May 2008 and August 2012 in Figure 2a $(n=61)$. The Fm values range from 0.103-0.747. Model II (geometric mean) linear regression analysis of Fm vs. [DOC] resulted in a significant anticorrelation (not shown; $\mathrm{R}^{2}=0.21, p<0.0001$ ). This anticorrelation between $\mathrm{Fm}$ and $[\mathrm{DOC}]$ indicates that low- ${ }^{14} \mathrm{C}$ carbon is being added as [DOC] increases in our MQ water. A Keeling plot of the data $\left([\mathrm{DOC}]^{-1}\right.$ vs. Fm; $\left.\mathrm{R}^{2}=0.23, p<0.0001\right)$ reveals that the Fm value of added extraneous carbon ( $y$ intercept) is ${ }^{14} \mathrm{C}$-free $(\mathrm{Fm}=-0.047 \pm 0.055$; Figure $2 \mathrm{~b})$. Sources of ${ }^{14} \mathrm{C}$-free extraneous carbon in MQ water may result from the PVC pipes feeding the MQ system, the walls of the MQ system itself (comprised of glass, PTFE and HDPE), or the Tygon ${ }^{\circledR}$ tubing used to dispense water into glass storage bottles prior to UV oxidation. Presently, we use re-irradiated water, whose [DOC] is $0.2 \mu \mathrm{M} \mathrm{C}$, as the diluent for our seawater samples. The previous sample or standard oxidized in the reactor is the source of this re-irradiated water.

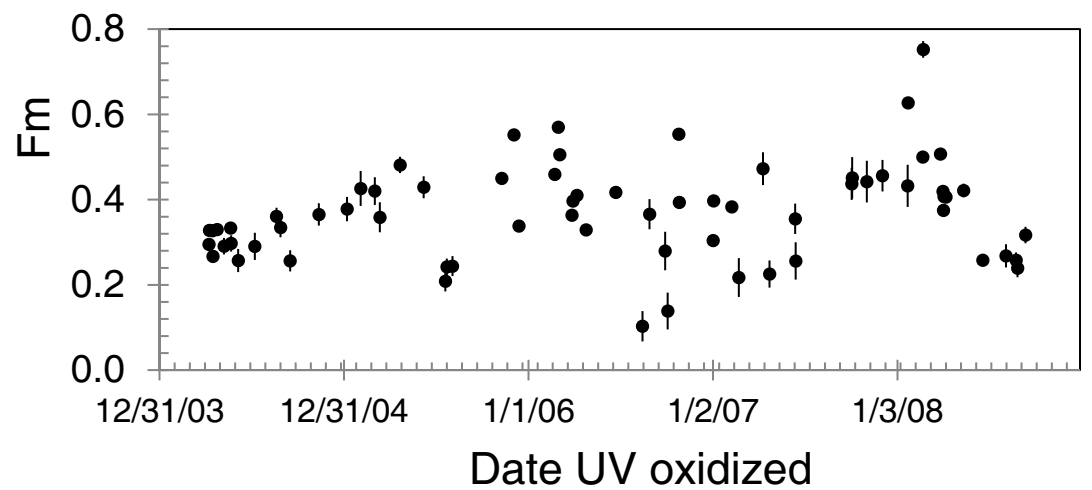

Figure 2a Date UV oxidized vs. Fm for the MQ water samples. Error bars are $1 \sigma$ errors.

To test for the presence of memory, residual DOC that remains in the UV oxidation vessel from one sample to the next, we plotted the Fm value of the MQ water sample vs. the Fm value of the previous seawater or standard sample oxidized in the quartz vessel (Figure 3). This is the most sensitive test of possible memory because even 1-2 $\mu \mathrm{g}$ of residual carbon added to a MQ sample (which ranges from 8-14 $\mu \mathrm{g} \mathrm{C}$ ) could significantly change the Fm value of DOC in MQ water. A least-squares fit through the data shows no significant correlation $\left(\mathrm{R}^{2}=0.0025\right)$. Moreover, we note that the Fm values for MQ water run after OX-I standards, whose Fm values are high (1.040), are not significantly higher than other MQ results. Thus, we conclude that sample memory is negligible for our analyses. 


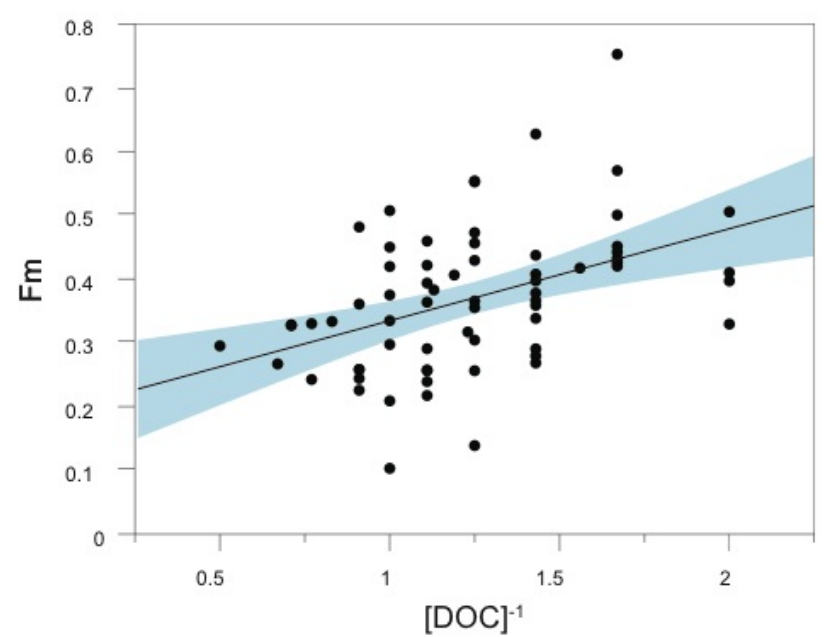

Figure $2 \mathrm{~b}$ Keeling plot of $[\mathrm{DOC}]^{-1}$ vs. Fm for the MQ water samples. The line is the Model II least-squares fit (geometric mean) regression analysis $\left(\mathrm{R}^{2}=0.189, p<0.0002\right)$. The $y$ intercept is $\mathrm{Fm}=-0.043 \pm 0.055$. The shaded area represents the $95 \%$ confidence limits $(\alpha=0.05)$ of the data.

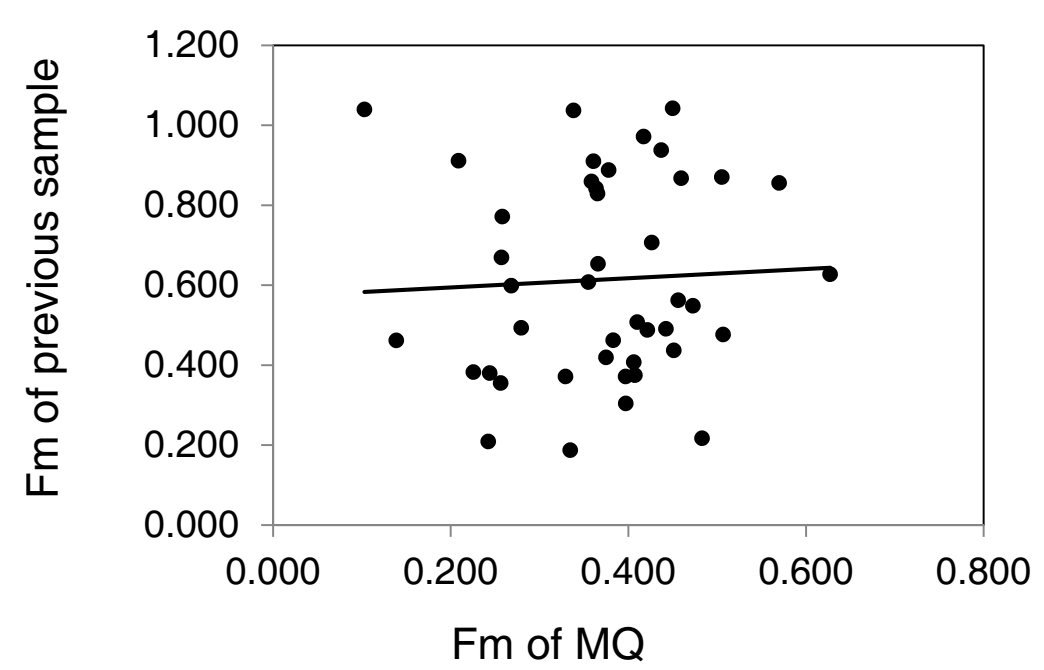

Figure 3 Fm of MQ water vs. Fm of sample UV oxidized just prior to the MQ water sample. Line is the least-squares fit of the data $\left(R^{2}=0.0025\right)$. Results show there is no significant memory of the previous sample oxidized in MQ water DOC samples (see text for detail).

\section{SUMMARY AND METHODOLOGICAL RECOMMENDATIONS}

We have determined that the total uncertainty of our DOC $\Delta^{14} \mathrm{C}$ measurements of seawater duplicates is $\pm 4.0 \%$. Seawater DOC samples that have been thawed and refrozen for $\geq 21$ days prior to UV oxidation have larger total $\Delta^{14} \mathrm{C}$ uncertainties $( \pm 10 \%)$. These samples also have higher [DOC] values after having been thawed and refrozen, though the reasons for this are not clear.

Recommendations from the results of this study are 1) to perform regular analyses of standards and diluent water (e.g. MQ) to allow for accurate assessment of extraneous carbon; 2) to thaw samples 
immediately before and only once prior to UV oxidation; 3) to avoid the use of DOC-leachable plumbing (such as PVC pipe) in both systems feeding MQ water and inside MQ systems; and 4) consider the use of DOC-free diluents (i.e. pre-UV oxidized MQ or sample water).

\section{ACKNOWLEDGMENTS}

Thanks to John Southon and colleagues for assistance with the AMS analyses, Steven Beaupré for continued support and valuable advice, and an anonymous reviewer for helpful comments. We acknowledge NSF Chemical Oceanography program (OCE- 0502619, OCE-0961980) and NSF Office of Polar Programs (ARC-1022716) for funding.

\section{REFERENCES}

Beaupré SR, Druffel ERM. 2009. Constraining the propagation of bomb-radiocarbon through the dissolved organic carbon (DOC) pool in the northeast Pacific Ocean. Deep-Sea Research I 56(10):1717-26.

Beaupré SR, Druffel ERM, Griffin S. 2007. A low-blank photochemical extraction system for concentration and isotopic analyses of marine dissolved organic carbon. Limnology and Oceanography 5:174-84.

Griffin S, Beaupré SR, Druffel ERM. 2010. An alternate method of diluting dissolved organic carbon seawater samples for ${ }^{14} \mathrm{C}$ analysis. Radiocarbon $52(2-3): 1224$ 9.

Southon J, Santos GM, Druffel-Rodriguez K, Druffel E, Trumbore S, Xu X, Griffin S, Ali S, Mazon M. 2004.
The Keck Carbon Cycle AMS laboratory, University of California, Irvine: initial operation and a background surprise. Radiocarbon 46(1):41-9.

Vogel JS, Southon JR, Nelson DE. 1987. Catalyst and binder effects in the use of filamentous graphite for AMS. Nuclear Instruments and Methods in Physics Research B 29(1-2):50-6.

Williams PM, Druffel ERM. 1987. Radiocarbon in dissolved organic carbon in the central North Pacific Ocean. Nature 330(6145):246-8.

Williams PM, Oeschger H, Kinney P. 1969. Natural radiocarbon activity of the dissolved organic carbon in the north-east Pacific Ocean. Nature 224(5216):2568 . 